\title{
The association between different hormone replacement therapy use and the incidence of lung cancer: a systematic review and meta-analysis
}

\author{
Hui Wen ${ }^{1 *}$, Xuefeng Lin ${ }^{2 *}$, Daqiang Sun ${ }^{1,3}$ \\ ${ }^{1}$ Graduate School, Tianjin Medical University, Tianjin, China; ${ }^{2}$ Tianjin Medical College, Tianjin, China; ${ }^{3}$ Department of Thoracic Surgery, Tianjin \\ Chest Hospital of Tianjin University, Tianjin, China \\ Contributions: (I) Conception and design: D Sun; (II) Administrative support: D Sun; (III) Provision of study materials or patients: X Lin; (IV) \\ Collection and assembly of data: X Lin; H Wen (V) Data analysis and interpretation: H Wen; (VI) Manuscript writing: All authors; (VII) Final \\ approval of manuscript: All authors. \\ \#These authors contributed equally to this work. \\ Correspondence to: Daqiang Sun. Department of Thoracic Surgery, Tianjin Chest Hospital of Tianjin University, No. 261, Taierzhuang South Road, \\ Jinnan District, Tianjin 300000, China. Email: sdqmd@163.com.
}

Background: Many peri- and postmenopausal women use hormone replacement therapy (HRT) to relieve menopausal symptoms. However, the side effects of different HRT use (ever/current/former vs. never HRT use) on lung cancer risk in women were not completely consistent. Thus, we conducted this meta-analysis to examine the connection between current, former or ever HRT use and the incidence of lung cancer among women.

Methods: We systematically searched the PubMed, Web of Science, EMBASE, Cochrane Library, SCOPUS, China National Knowledge Infrastructure, Wanfang and VIP databases to identify relevant articles published from the inception of the respective databases to February 18, 2022. On the relationship between different HRT use and the incidence of lung cancer among women. Relevant risk estimates [relative risks (RRs), odds ratio (OR)] were combined based on specific study types. The Newcastle-Ottawa Scale was used to evaluate the quality of included studies. This analysis has been registered in the International prospective register of systematic reviews (PROSPERO; CRD42020219728). Publication bias was tested based on Egger's and Begg's tests.

Results: A total of 22 studies (13 prospective cohort studies and 9 case-control studies) were included, comprising 911,194 participants and 17,329 patients. Compared to never HRT users, in pooled cohort studies, current HRT users had a statistically decreased risk of lung cancer [RR $0.91,95 \%$ confidence interval (CI): $0.86-0.97, \mathrm{I}^{2}=22.9 \%$ ], and similar results were found among the postmenopausal women with current HRT use (RR 0.91, 95 CI: 0.85-0.98, $\mathrm{I}^{2}=36 \%$ ), while in pooled case-control studies, ever HRT users had a decreased risk of incidence of lung cancer [odds ratio (OR) $0.75,95 \%$ CI: $0.69-0.81, \mathrm{I}^{2}=0 \%$ ] as did female non-smokers with ever HRT use (OR 0.76, 95\% CI: 0.66-0.87, $\mathrm{I}^{2}=36.8 \%$ ).

Conclusions: Current or ever HRT use is partly correlated with the decreased incidence of lung cancer in women. Concerns about the incidence of lung cancer can be reduced when perimenopausal and postmenopausal women use current HRT to reduce menopausal symptoms. Meanwhile, given the roles of hormone receptors and relevant genes single nucleotide polymorphism (SNPs) among females, HRT use should be cautiously administered and individualized.

Keywords: Current former or ever HRT use; meta-analysis; lung cancer

Submitted Aug 13, 2021. Accepted for publication Feb 21, 2022.

doi: $10.21037 /$ jtd-22-48

View this article at: https://dx.doi.org/10.21037/jtd-22-48 


\section{Introduction}

Lung cancer is a huge global health problem with a considerable social and economic burden (1), and it is the leading cause of cancer-related mortality worldwide $(2,3)$. Epidemiological studies showed that approximately 1.8 million people died of lung cancer worldwide in 2020 $(2,3)$. It is estimated that in 2021, about 235,760 new lung cancer and bronchus cancer cases will be diagnosed in the United States (US) (3). In the US, the proportion of nonsmoking females with lung cancer is $19 \%$, while that of nonsmoking males is only $9 \%$ (4). Due to the higher incidence rate of lung cancer among female non-smokers than male non-smokers $(5,6)$, the role of many reproductive factors, especially estrogen and its receptors, has been considered in the occurrence and development of lung cancer (7). Hence research needs to be conducted to determine whether exogenous hormone therapy increases the risk of lung cancer. Hormone replacement therapy (HRT), which provides an alternative delivery method of endogenous hormones, usually consists of estrogen with or without progesterone. Many peri- or postmenopausal women use HRT to reduce postmenopausal syndromes (e.g., vasomotor symptoms and urogenital atrophy) due to ovarian failure (8). In the process of relieving postmenopausal symptoms, the benefits and risks of HRT should be considered. Cagnacci et al. (9-11) noted that HRT appears to be beneficial for coronary disease and to reduce all-cause mortality in early postmenopausal women. However, research results on the benefits of HRT for malignant diseases, especially lung cancer, are inconsistent $(12,13)$. Previous studies have shown that ever HRT users had a lower risk of lung cancer $(14,15)$; however, an increased risk of lung adenocarcinoma has been reported in female non-smokers with ever HRT use (16), and there is little connection between ever HRT use and the risk of lung cancer (17). Meanwhile, HRT therapy can be classified based on HRT use (current, former, never, or ever) $(13,18)$. A large prospective cohort study comprising 75,587 female participants suggested that current HRT use reduced the incidence of non-small cell lung cancer (NSCLC) among women (19), but some prospective cohort studies have shown little connection between current HRT and the incidence of non-small cell lung cancer (20,21). Rodriguez et al. (22) pointed that Current HRT users were associated with a reduced incidence of lung cancer, compared with never users, while Former HRT use was not associated with lung cancer risk. Considering many large cohort studies have inconsistent results about the connection between current/former/eve HRT use and the incidence of lung cancer $(13,18,20-30)$, a meta-analysis to explore the association is needed. Compared with previous studies, in order to eliminate the heterogeneity of HRT use states, we divided HRT use into ever, current, former and never use, and then analyzed the association between different HRT use (current, former, or ever) and risk of lung cancer. Hence, to address the conflicting results of lung cancer risk in relation to HRT use, we conducted a quality meta-analysis to examine the relationship between different HRT use and the incidence of lung cancer. To exclude the effects of tobacco, research on the association between ever HRT use and the incidence of lung cancer among female non-smokers was also conducted.

We present the following article in accordance with the MOOSE reporting checklist (available at https://jtd. amegroups.com/article/view/10.21037/jtd-22-48/rc).

\section{Methods}

This meta-analysis has been registered with the International Prospective Register of Systematic Reviews (PROSPERO) (Identifier: CRD42020219728).

\section{Searching strategy}

We systematically searched PubMed, Web of Science, EMBASE, The Cochrane Library, SCOPUS, China National Knowledge Infrastructure, Wanfang and VIP databases for articles published from the inception of these databases to February 18, 2022. The search was conducted using the following relevant terms: "Estrogens", "Estrogens, Conjugated", "Estrogen replacement therapy", "Hormone replacement therapy", "Hormones", "Progestins", "Estrogen Receptor Modulators", "Hormones, Hormone Substitutes, and Hormone Antagonists", "Gonadal Hormones", "Estradiol", "Lung Neoplasms", and "Small Cell Lung Carcinoma", and "Carcinoma, Non-SmallCell Lung". Searching strategy can be seen in Appendix 1. Additionally, we manually searched and systematically reviewed the reference lists of the included studies. Without language restrictions, all searches were conducted independently by two reviewers (Lin and Wen). Any disagreements were checked by a 3 rd reviewer (Sun) and resolved through discussion. Inclusion criteria in PICO format have been provided in Appendix 2.

\section{Types of studies and participants}

Prospective cohorts and case-control trials were included 
in this meta-analysis. Inclusion criteria: (I) the minimum number of participants in each original document had to be $>30$; (II) studies should evaluate or assess the association between HRT use and the incidence of lung cancer; (III) the primary exposure of interest in each included article should be HRT use [i.e., ever/current/former HRT use vs never HRT use]; (IV) the risk estimates [odds ratio (OR), relative risk (RR), or hazard ratio (HR)] and 95\% confidence intervals (CIs) had to be reported in the articles or information had to be available that enabled us to calculate the relevant risk estimates; (V) The cohort study included women of any age without lung cancer before the trial; (VI) non-smokers were defined as someone who had never smoked or smoked less than 6 months or less than 100 cigarettes during his/her lifetime. The exclusion criteria: (I) studies did not consider the association between HRT use and the incidence of lung cancer; (II) without any risk estimates (ORs, RRs, or HRs and 95\% CIs) information; (III) duplicate publications; (IV) participants from the same clinical trial; (V) conference abstracts, review articles, letters and unpublished manuscripts.

\section{Types of interventions and outcomes}

In this analysis, we studied the etiological effects of different HRT use on lung cancer. We divided HRT use into current use, former use, ever use or never use. The primary outcome was the incidence rate of lung cancer in relation to different HRT uses (current, former, or ever) compared to no HRT use among women. The secondary outcome was the incidence of lung cancer among postmenopausal women and female non-smokers with ever HRT use compared to never HRT use. Lung cancer is usually classified as nonsmall cell lung cancer (NSCLC) or small cell lung cancer. Current HRT users were defined as those who used HRT after the baseline (the baseline was defined as the time at which the participants entered into the cohort studies). Former users were defined as those who had used HRT at any time before the baseline. Ever users were defined as those who used HRT but no indication of when they used it, and included former users and current users $(13,18)$. All retrieved publication references were exported to EndNote X9, duplicates were removed based on a combination of automated and manual checking. The preliminary screening based on the title and abstract evaluation was performed by two independent reviewers (Wen and Lin), and then two reviewers (Wen and Lin) will independently assess eligible articles through the full text against the inclusion and exclusion criteria, and any discrepancies will be resolved by the third reviewer (Sun).

\section{Data extraction and quality assessment}

All data were screened and extracted by two reviewers (Lin and Wen) from original articles. A 3rd reviewer (Sun) cross-observed the data to confirm the accuracy. The required data were collected in a standardized observation table. The collected information included the journal name, name of the first author, publication date, country of participants, enrollment period, study type, follow-up time, age, HRT use, number of case events, number of participants, adjustment variables, adjusted risk estimates, Calculated ORs and 95\% CIs, relevant information about users' BMI and smoking status. If there were two risk estimates for 1 article, we chose the one with the higher credibility. The articles included had to qualify under the Newcastle-Ottawa Quality Assessment Scale (NewcastleOttawa Scale; NOS). NOS quality scores range from 0 to 9. Previous studies $(31,32)$ considered a NOS score $\geq 6$ to indicate high research quality and $\leq 5$ to indicate low research quality, which is consistent with our metaanalysis results. When the quality assessments of the two researchers (Lin and Wen) for an article differed, the disputed issue was resolved through discussion between the two researchers, or, if necessary, the $3 \mathrm{rd}$ researcher (Sun) intervened. We contacted the original authors of included studies for clarification when needed.

\section{Data and statistical analysis}

This specific meta-analysis was based on different study types; that is, pooled cohort and case-control studies. In the pooled cohort studies, we combined the RR estimates and $95 \%$ CIs for analysis. In data synthesis, the hazard ratio (HR) was considered equivalent to RR (33). As results on the incidence of lung cancer are relatively rare, the HR was considered to be an approximate value of relative risk (RR) in this meta-analysis. Fixed- or random-effects models were used to estimate the relationship between different HRT use and the incidence of lung cancer among women. The subgroup analyses examined the risk of lung cancer among non-smoking women, postmenopausal women, and women over 50 years old with ever HRT use. In the case-control studies, we extracted the corresponding original data to calculate ORs and then combined them for research. In the pooled case-control studies, we studied the relationship 


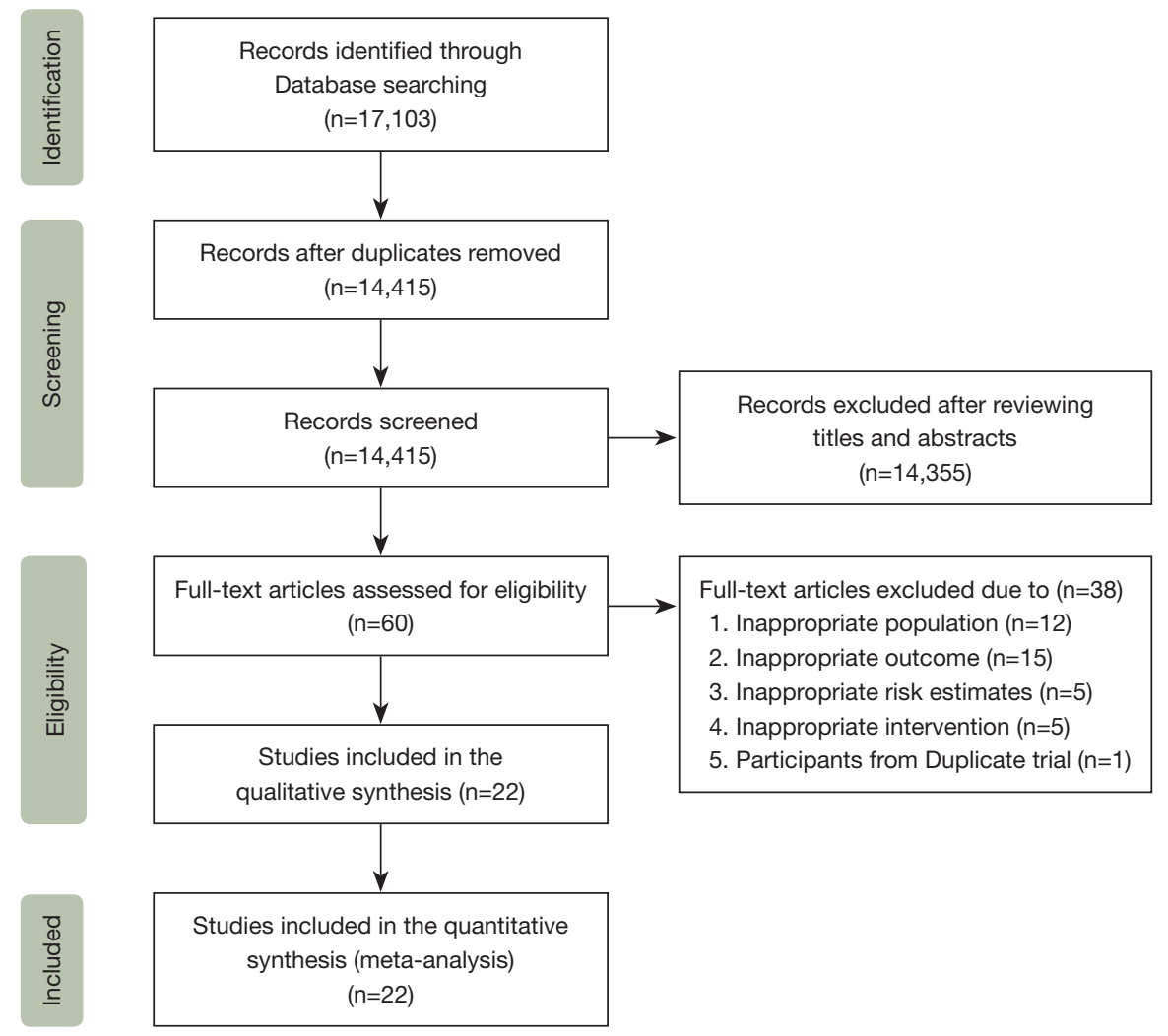

Figure 1 Flow chart of the article screening process.

between ever HRT use and the incidence of lung cancer among all women. The subgroup analyses examined the relationship between ever use of HRT and the incidence of lung cancer among female non-smokers and underweight/ normal/overweight/obese women, Subgroup analysis also examined the effect of ever HRT on the incidence of non-small cell lung cancer. In these analyses, we used Cochrans Q-test and Higgins $\mathrm{I}^{2}$ statistics to evaluate the heterogeneity of included studies; when the $\mathrm{P}<0.1$ or $\mathrm{I}^{2}>50 \%$, heterogeneity was assumed, and we combined the risk estimates using a random-effects model; otherwise, we used a fixed-effects model. Using subgroup and metaregression analyses, possible sources of heterogeneity were identified. The sensitivity analysis method was used to judge the robustness of the results. Every study was removed in turn, and the eligible studies were subsequently re-analyzed by the meta-analysis to observe whether the total combined effect changed significantly. The corresponding publication bias was analyzed using Begg's and Egger's tests. The relevant data were calculated using Stata software Version 16.0 (Stata Corp, College Station, TX, USA).

\section{Results}

\section{Search results and characteristics of eligible studies}

Figure 1 provides a flow chart of the process used to screen the articles. A total of 17,103 articles were retrieved from these 8 databases (the PubMed, Web of Science, EMBASE, The Cochrane Library, SCOPUS, China National Knowledge Infrastructure, Wanfang and VIP databases). After removing duplicate articles and articles based on a review of the titles and abstracts, 60 articles remained. Based on the inclusion and exclusion criteria, an additional 38 articles were excluded for the following reasons: 15 articles reported no relevant outcomes (without information about the incidence of lung cancer); the relevant risk estimates of 5 articles were not available or could not be calculated; 5 studies did not provide relevant HRT intervention information; 12 studies included inappropriate participants (e.g., with lung cancer before cohort trials); and 1 article considered the relevant outcome that current HRT use can reduce the incidence of NSLC, but the study included participants from duplicate cohort trial—prostate, 
lung, colorectal, and ovary (PLCO) trial (19). Ultimately, 13 potentially eligible cohort studies $(13,18,20-30)$ and 9 case-control studies (34-42), including 17,329 patients with lung cancer, were included in the meta-analysis.

In the cohort studies, each trial used a prospective cohort. The included articles were published between 2005 and 2020, and had a minimum average follow-up time of 4.1 years. These relevant cohort studies $(18,20-22)$ defined participants as postmenopausal women. HRT use was divided into never, current, former or ever use. The adjusted risk estimates were extracted from the original documents. In the case-control studies, the articles were published between 2003 and 2013. The number of relevant participants and patients was extracted from the raw data, and then we calculated the corresponding ORs. The NOS was used to score each included article in relation to 8 items. All of the articles included in this analysis had a score $\geq 6$. Thus, the quality of each article was generally high. We presented participant information from the included studies and NOS scores for each study's risk of bias assessment in Tables 1,2. Smoking status was divided into non-smokers and ever-smokers.

\section{Meta-analysis}

As Figure 2 shows, 7 articles were included in the analysis to examine the association between current HRT use and the incidence of lung cancer. The relative risks were combined using a fixed-effects model. Compared with never HRT users, current HRT users had a lower risk of lung cancer (RR 0.91, 95\% CI: 0.86-0.97; Egger's test $\mathrm{P}=0.82$ ). The subgroup analysis of the risk of lung cancer among postmenopausal women showed that there was a statistical decrease in the incidence of lung cancer among current HRT users (RR 0.91, 95\% CI: 0.85-0.98; Egger's test $\mathrm{P}=0.49$ ). Among all female participants and postmenopausal users, the funnel plots for analyses of the association between lung cancer incidence and current HRT use were symmetrical, indicating no significant evidence for publication bias. Egger's tests did not show statistically significant publication bias.

As Figure 3 shows, 9 case-control experiments were included in the meta-analysis. Using fixed-effects models, the unadjusted odds ratios were combined. Notably, Compared with no HRT use, ever HRT using women had a low risk of lung cancer (OR 0.75, 95\% CI: 0.69-0.81; Egger's test $\mathrm{P}=0.92$ ), as did female non-smokers (OR 0.76 , 95\% CI: 0.66-0.87; Egger's test $\mathrm{P}=0.25$ ). As Figure 4 shows, the Begg's funnel plot did not reveal any publication bias in the pooled case-control studies in relation to the association between ever HRT use and the risk of lung cancer among all women. Egger's tests revealed no evidence of statistically significant publication bias in the pooled case-control studies for the analyses of the association between lung cancer incidence and female ever HRT users or nonsmoking users, Compared with no HRT use.

Table 3 shows the summary risk estimates of the association between HRT and lung cancer. Thirteen prospective cohort studies were eligible for the metaanalysis, we found that the current use of HRT has a slight effect on reducing lung cancer in postmenopausal women and even all women. However, Compared to never HRT use, there was no significant correlation between the incidence of lung cancer and former or ever HRT use (RR 0.96, 95\% CI: 0.90-1.02, P=0.16; RR 0.96, 95\% CI: 0.90 $1.03 ; \mathrm{P}=0.23$ ), or the incidence of lung cancer and female non-smokers who were ever HRT users (RR 0.99, 95\% CI: $0.85-1.15 ; \mathrm{P}=0.88)$. Considering the global mean age of menopause is around 50 years (43) and individuals aged over 50 years old were at high risk of developing cancer (44), we pooled cohort articles with participants older than 50 years old at the baseline and found that current and ever HRT users over 50 years of age had a statistically lower risk of lung cancer, compared to no HRT users. And we conducted a meta-analysis of 9 case-control studies, compared to no HRT use, ever user has a lower incidence in both lung cancer and non-small cell lung cancer; In non-smokers with ever HRT use, the incidence of lung cancer is reduced. Considering the effect of body mass index (BMI) on lung cancer incidence (45), we conducted the analyses stratified by BMI. We found that ever use of HRT can reduce the incidence of lung cancer among female participants with $\mathrm{BMI}<25$, compared with no HRT users, but no statistical association was found between ever HRT use and the incidence of lung cancer among obese/overweight female participants. Meanwhile, the pooled univariate analyses results need to be interpreted with caution.

\section{Discussion}

Cancer risk factors involved intrinsic and non-intrinsic factors (46), and the occurrence and development of lung cancer is a multi-factor and multi-step process (47). In addition to intrinsic risk factors for lung cancer, there are also many non-intrinsic risk factors including: tobacco smoking (48), environmental pollutants (48-49), second- 
Table 1 Characteristics of included cohort studies

\begin{tabular}{|c|c|c|c|c|c|c|c|c|c|c|c|c|c|c|}
\hline \multirow{2}{*}{ Journal } & \multirow{2}{*}{ Source } & \multirow{2}{*}{ Country } & \multirow{2}{*}{$\begin{array}{l}\text { Enrollment } \\
\text { period }\end{array}$} & \multirow{2}{*}{$\begin{array}{l}\text { Follow-up } \\
\text { (years) }\end{array}$} & \multirow{2}{*}{$\begin{array}{l}\text { Age at } \\
\text { baseline }\end{array}$} & \multirow{2}{*}{ Study type } & \multicolumn{3}{|c|}{ HRT status } & \multirow{2}{*}{$\begin{array}{c}\text { Cases/ } \\
\text { participants }\end{array}$} & \multirow{2}{*}{$\begin{array}{l}\text { HRT } \\
\text { type }\end{array}$} & \multirow{2}{*}{ Non-smokers } & \multirow{2}{*}{$\begin{array}{l}\text { NOS } \\
\text { assessment }\end{array}$} & \multirow{2}{*}{ Adjustment variables } \\
\hline & & & & & & & Former HRT use & Current HRT use & Ever HRT use & & & & & \\
\hline $\begin{array}{l}\text { International Journal of } \\
\text { Clinical Oncology }\end{array}$ & $\begin{array}{l}\text { Omar Abdel- } \\
\text { Rahman } 2020\end{array}$ & USA & 1993-2001 & $11.34^{\mathrm{A}}$ & $55-74$ & $\begin{array}{l}\text { Prospective } \\
\text { cohort }\end{array}$ & $0.94(0.81-1.10)^{b}$ & $0.84(0.74-0.95)^{b}$ & $0.88(0.78-0.98)^{b}$ & $1,379 / 77,911$ & HRT & $0.88(0.66-1.23)^{b}$ & 6 & $\begin{array}{l}\text { Age, body mass index, study arm, race, cigarette smoking, and family history } \\
\text { of lung cancer }\end{array}$ \\
\hline Hormones and Cancer & $\begin{array}{l}\text { Marianne Holm } \\
2018\end{array}$ & Denmark & 1993-1997 & $15.9^{\mathrm{B}}$ & $50-64$ & $\begin{array}{l}\text { Prospective } \\
\text { cohort }\end{array}$ & $0.96(0.78-1.18)^{b}$ & $0.99(0.83-1.17)^{b}$ & - & $694 / 29,152$ & HRT & - & 6 & $\begin{array}{l}\text { Age, age at menarche; parity and age at first childbirth, history of oral } \\
\text { contraceptive pill use; adult attained height, education level; baseline alcohol } \\
\text { intake, BMI; physical activity, smoking and diet }\end{array}$ \\
\hline J Thorac Oncol & $\begin{array}{l}\text { Ann G. Schwartz } \\
2015^{* *}\end{array}$ & USA & 1993-1998 & $14^{\mathrm{B}}$ & $50-79$ & $\begin{array}{l}\text { Prospective } \\
\text { cohort }\end{array}$ & $1.02(0.90-1.16)^{b}$ & $0.91(0.81-1.03)^{b}$ & - & 2,467/160,855 & HRT & - & 8 & $\begin{array}{l}\text { Age at screening (continuous), race/ethnicity, pack-years of smoking } \\
\text { (categories), education, US region, history of emphysema, history of asthma, } \\
\text { BMI, and family history of cancer; Models were stratified by a 5-year age } \\
\text { group, baseline hysterectomy status, study type (OS or trial arm for clinical } \\
\text { trial participants), and WHI extension study participation }\end{array}$ \\
\hline Lung Cancer & Hui Shan Tan 2015 & Singapore & 1994-1997 & $15.8^{\mathrm{A}}$ & $50-64$ & $\begin{array}{l}\text { Prospective } \\
\text { cohort }\end{array}$ & - & - & $0.88(0.62-1.25)^{b}$ & $311 / 28,222$ & HRT & $0.86(0.59-1.26)^{\mathrm{b}}$ & 8 & $\begin{array}{l}\text { Age at entry (continuous), ethnicity (Chinese, Malay, Indian, others), BMI } \\
\text { (continuous), smoking status (never smokers, ex-smokers, occasional } \\
\text { smokers, current smokers) }\end{array}$ \\
\hline Cancer Causes Control & $\begin{array}{l}\text { Louise A. Brinton } \\
\quad 2012\end{array}$ & USA & 1996-1997 & $5.4^{A}$ & $50-72$ & $\begin{array}{l}\text { Prospective } \\
\text { Cohort }\end{array}$ & $0.98(0.83-1.14)^{\mathrm{a}}$ & $0.96(0.84-1.10)^{\mathrm{a}}$ & $0.97(0.86-1.09)^{\mathrm{a}}$ & $2,097 / 118,008$ & ET & $0.90(0.59-1.38)^{\mathrm{a}}$ & 8 & $\begin{array}{l}\text { Age, race, age at menarche, menopausal type and age, BMI, emphysema } \\
\text { diagnosis, cigarette smoking status and number of cigarettes/day, and other } \\
\text { hormone therapy formulations }\end{array}$ \\
\hline $\begin{array}{l}\text { Cancer Epidemiol } \\
\text { Biomarkers Prevention }\end{array}$ & $\begin{array}{l}\text { Jessica Clague } \\
2011^{\star \star}\end{array}$ & USA & 1995-1996 & 11 & $N G$ & $\begin{array}{l}\text { Prospective } \\
\text { cohort }\end{array}$ & $0.98(0.79-1.21)^{\mathrm{a}}$ & $0.94(0.78-1.13)^{a}$ & $0.95(0.80-1.13)^{\mathrm{a}}$ & $727 / 60,592$ & HRT & $1.06(0.76-1.50)^{a}$ & 6 & $\begin{array}{l}\text { Age at baseline, race, smoking status/pack-years combination (never, former } \\
\text { light, former heavy, current light, current heavy), type of menopause, and BMI }\end{array}$ \\
\hline $\begin{array}{l}\text { Cancer Epidemiol } \\
\text { Biomarkers Prevention }\end{array}$ & $\begin{array}{l}\text { Christina S. Baik } \\
2010^{\star *}\end{array}$ & USA & $1984+$ & 22 & $38-87$ & $\begin{array}{l}\text { Prospective } \\
\text { cohort }\end{array}$ & $0.91(0.79-1.04)^{b}$ & $0.99(0.86-1.14)^{b}$ & - & $1,729 / 107,171$ & HRT & - & 6 & $\begin{array}{l}\text { Age at menopause, age at menarche, parity, PMH use, OCP use, smoking } \\
\text { status, age at start smoking, cigarettes per day, time since quitting, fruit/ } \\
\text { vegetable intake, BMI, and environmental smoking exposure }\end{array}$ \\
\hline Menopause & $\begin{array}{l}\text { Joshua R. Smith } \\
\quad 2009\end{array}$ & USA & 1972-1974 & 31 & $31-79$ & $\begin{array}{l}\text { Prospective } \\
\text { cohort }\end{array}$ & - & - & $1.13(0.73-1.73)^{b}$ & $87 / 2,861$ & HRT & - & 7 & Adjusted for age, BMI, education category, marital status, and smoking status \\
\hline $\begin{array}{l}\text { Cancer Epidemiol } \\
\text { Biomarkers Prevention }\end{array}$ & $\begin{array}{l}\text { Carmen Rodriguez } \\
2008^{* *}\end{array}$ & USA & $1992+$ & 11 & $50-74$ & $\begin{array}{l}\text { Prospective } \\
\text { cohort }\end{array}$ & $0.89(0.73-1.07)^{\mathrm{a}}$ & $0.76(0.62-0.92)^{\mathrm{a}}$ & - & 659/72,772 & HRT & - & 8 & $\begin{array}{l}\text { Age at interview, smoking status, spousal tobacco exposure in } 1992, \text { BMI in } \\
\text { 1992, age at menopause, education, weekly servings of fruit, physical activity, } \\
\text { total } \beta \text {-carotene intake, and oral contraceptive use }\end{array}$ \\
\hline $\begin{array}{l}\text { American Journal of } \\
\text { Epidemiol }\end{array}$ & $\begin{array}{l}\text { Jocelyn M. Weiss } \\
2008\end{array}$ & China & 1996-2000 & $4.1^{\mathrm{A}}$ & $40-70$ & $\begin{array}{l}\text { Prospective } \\
\text { cohort }\end{array}$ & - & - & $0.5(0.16-1.56)^{b}$ & $220 / 71,314$ & HRT & $0.5(0.16-1.56)^{b}$ & 8 & Passive smoke exposure \\
\hline $\begin{array}{l}\text { International journal of } \\
\text { Cancer }\end{array}$ & $\begin{array}{l}\text { Geoffrey C. Kabat } \\
2007\end{array}$ & Canada & 1980-1985 & $16.4^{\mathrm{A}}$ & $40-59$ & $\begin{array}{l}\text { Prospective } \\
\text { cohort }\end{array}$ & - & - & $1.07(0.90-1.26)^{b}$ & $750 / 89,812$ & HRT & $0.95(0.58-1.55)^{b}$ & 7 & $\begin{array}{l}\text { Parity(4 levels), age at menarche ( } 4 \text { levels), age at first birth ( } 4 \text { levels), } \\
\text { menopausal status (pre-, peri- and postmenopausal), oral contraceptive } \\
\text { use (ever/never), hormone replacement use (ever/never), body mass index } \\
\text { (continuous), education ( } 3 \text { categories), smoking status (never, former smoker } \\
\text { and current smoker), pack-years of smoking (continuous), study center and } \\
\text { randomization group }\end{array}$ \\
\hline $\begin{array}{l}\text { International journal of } \\
\text { Cancer }\end{array}$ & Ying Liu 2005 & Japan & 1990-1994 & 8-12 & $40-69$ & $\begin{array}{c}\text { Prospective } \\
\text { cohort }\end{array}$ & - & - & $1.46(0.92-2.32)^{\mathrm{a}}$ & $153 / 44,677$ & HRT & $1.46(0.92-2.32)^{\mathrm{a}}$ & 7 & $\begin{array}{l}\text { Age, public health center (PHC) area, and passive smoking during childhood } \\
\text { or in the workplace }\end{array}$ \\
\hline
\end{tabular}

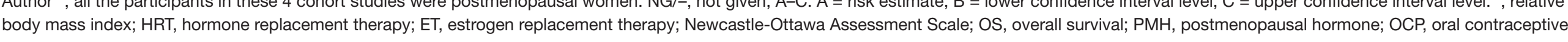


Table 2 Characteristics of the included case-control studies

\begin{tabular}{|c|c|c|c|c|c|c|c|c|c|}
\hline \multirow{2}{*}{ Journal } & \multirow{2}{*}{$\begin{array}{c}\text { Author and } \\
\text { publication date }\end{array}$} & \multirow{2}{*}{ Country } & \multirow{2}{*}{$\begin{array}{l}\text { Enrollment } \\
\text { period }\end{array}$} & \multirow{2}{*}{ Study type } & \multicolumn{2}{|c|}{ Lung cancer } & \multirow{2}{*}{$\begin{array}{c}\text { Female HRT } \\
\text { users } \\
\begin{array}{c}\text { Ever HRT use vs. } \\
\text { never use }\end{array}\end{array}$} & \multirow{2}{*}{$\begin{array}{c}\begin{array}{c}\text { Female never } \\
\text { smokers }\end{array} \\
\begin{array}{c}\text { Ever HRT use vs. } \\
\text { never use }\end{array}\end{array}$} & \multirow{2}{*}{$\begin{array}{c}\text { Nos } \\
\text { assessment }\end{array}$} \\
\hline & & & & & S or Nor & Non & & & \\
\hline $\begin{array}{l}\text { Cancer Causes } \\
\text { Control }\end{array}$ & Yen-Li Lo 2013 & China & 2002-2009 & Case-control & All & - & $0.75(0.63-0.91)$ & $0.75(0.63-0.91)$ & 8 \\
\hline $\begin{array}{l}\text { International } \\
\text { Journal of } \\
\text { Cancer }\end{array}$ & $\begin{array}{c}\text { Cari L. } \\
\text { Meinhold } 2011\end{array}$ & USA & 1998-2008 & Case-control & - & Non & $0.79(0.62-1.02)$ & $1.18(0.60-2.32)$ & 6 \\
\hline $\begin{array}{l}\text { Journal } \\
\text { of Clinical } \\
\text { Oncology }\end{array}$ & $\begin{array}{c}\text { Ann G. } \\
\text { Schwartz } 2007\end{array}$ & USA & 2001-2005 & Case-control & - & Non & $0.89(0.69-1.14)$ & - & 6 \\
\hline $\begin{array}{l}\text { Clinical Cancer } \\
\text { Research }\end{array}$ & $\begin{array}{c}\text { Matthew B. } \\
\text { Schabath } 2004\end{array}$ & USA & $N G$ & Case-control & All & - & $0.78(0.61-1.00)$ & $1.23(0.71-2.13)$ & 8 \\
\hline Contraception & $\begin{array}{l}\text { Alison M. Elliott } \\
2006\end{array}$ & UK & 1968-2004 & $\begin{array}{l}\text { Nested case- } \\
\text { control }\end{array}$ & All & - & $0.92(0.47-1.79)$ & - & 6 \\
\hline $\begin{array}{l}\text { International } \\
\text { Journal of } \\
\text { Epidemiol }\end{array}$ & $\begin{array}{c}\text { Michaela } \\
\text { Kreuzer } 2003\end{array}$ & Germany & 1990-1996 & Case-control & All & - & $0.75(0.60-0.93)$ & $0.78(0.42-1.45)$ & 7 \\
\hline
\end{tabular}

NG/-, not given; All, small cell lung cancer or non-small lung cancer; Non, non-small lung cancer; S, small lung cancer; HRT, hormone replacement therapy; NOS, Newcastle-Ottawa Assessment Scale.

hand smoke (50), and other factors [e.g., oncogenes (51), Oncogenic viruses (52), Radon (53)]. Meanwhile, A significantly higher incidence of lung cancer in female non-smokers than male non-smokers $(5,6)$. Yin et al. suggest that gender-associated factors might also play a role in lung cancer risk (54). Research on the effects of sex steroid hormones in lung cancer risk might explain the sex differences of lung cancer (55). The relationship between exogenous hormones and the incidence of lung cancer needs to be explored.

HRT is a general term used to describe exogenous estrogen therapy, estrogen plus progesterone therapy or other hormone therapy. HRT has been recognized as an effective method to alleviate peri- or postmenopausal symptoms. HRT can also benefit early postmenopausal women by preventing postmenopausal osteoporosis and reducing all-cause mortality. However, the effects of HRT on malignant tumors are mixed, A large multicentre study reported HRT use was inversely associated with the risk of colorectal cancer in women over 50 years old (56), and women with current HRT use had lower risks of overall mortality and colorectal cancer-specific mortality compared with women who had not previously used HRT (57). A large Swedish cohort study showed an overall reduced risk of esophageal adenocarcinoma in women with ever HRT use (58), which is the same as the research result by Lagergren et al. (59). Compared to no HRT use, ever users of HRT had a statistically decreased risk of primary liver cancer (60). For postmenopausal women treated with HRT, a reduced risk of developing cervical squamous cell carcinoma has been reported (61). The risk of kidney cancer can be reduced with up to 12 to 18 years of HRT use (62). Effects of HRT use might also reduce the risk of stomach cancer (63). However, results of the study on the effects of 
A Study ID RR $(95 \% \mathrm{Cl}) \quad$ Weight, $\%$

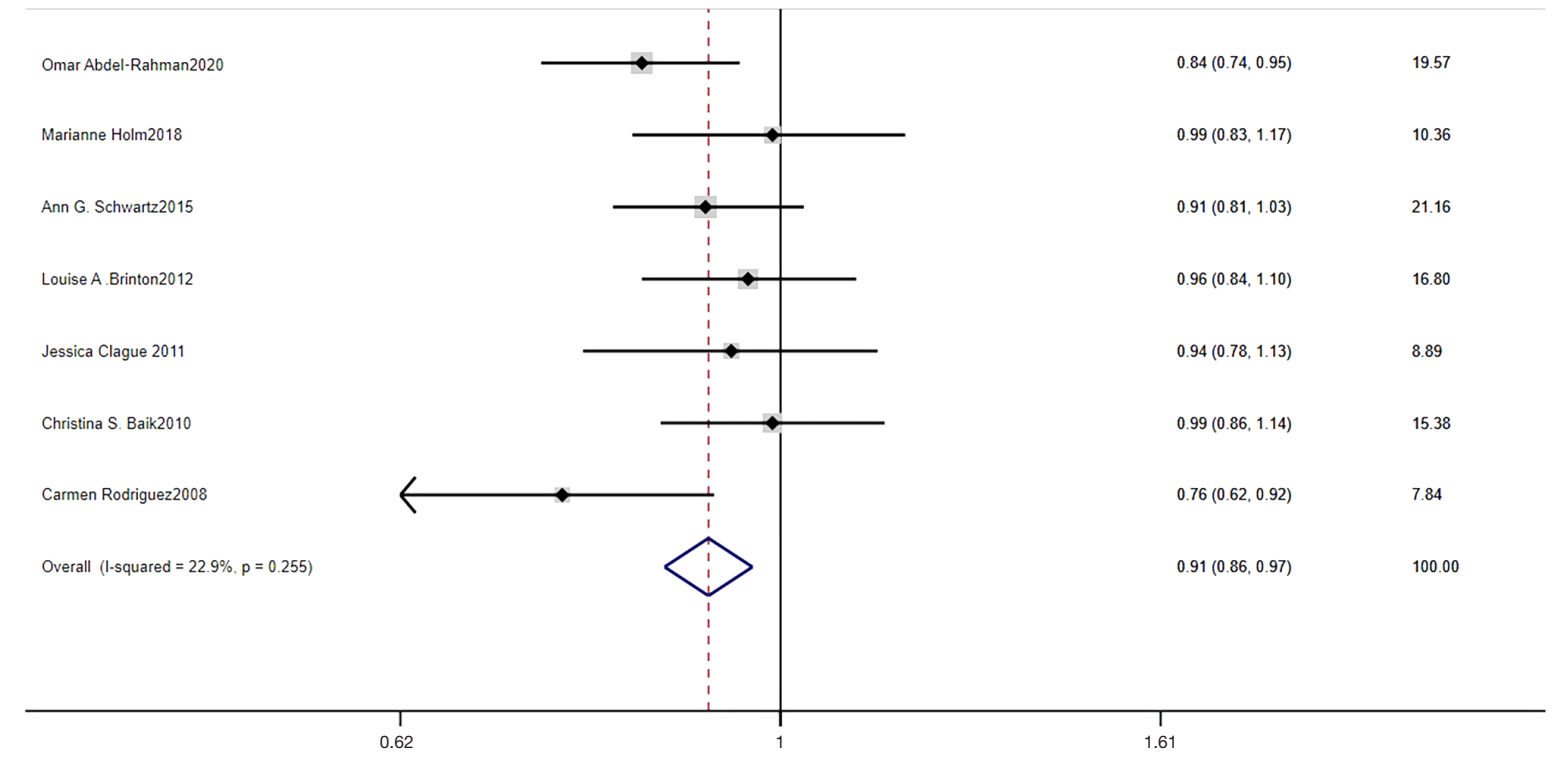

B

study

ID

RR $(95 \% \mathrm{Cl}) \quad$ Weight, $\%$

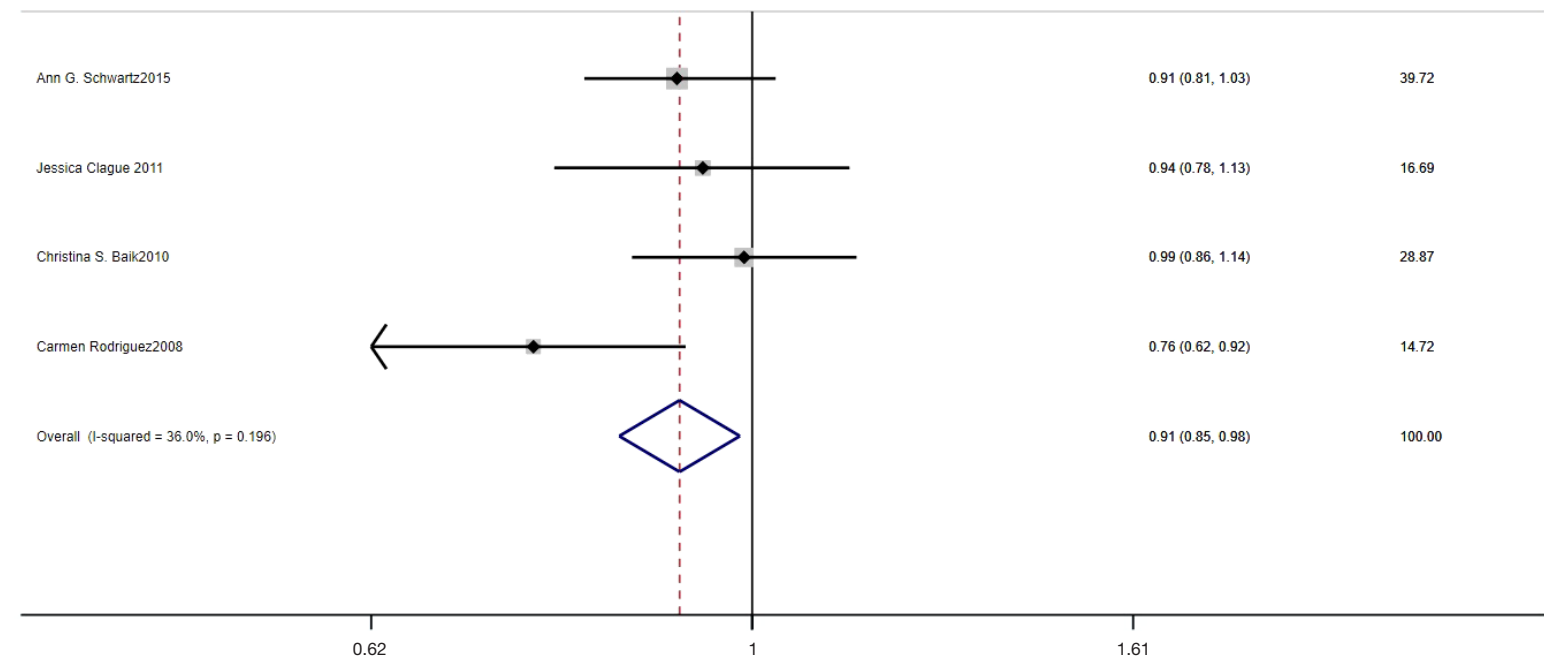

Figure 2 Forest plots of the association between current HRT use and the risk of lung cancer in pooled cohort studies. (A) The association among all participants; (B) the association among postmenopausal women. RR, relative risk; CI, confidence interval; HRT, hormone replacement therapy.

HRT use on BC (breast cancer) have shown that the use of HRT increases the risk of BC recurrence (64), especially in hormone receptor-positive patients.
Considering the effects of HRT use on lung cancer, similar to previous studies $(14,15)$, the results of our pooled case-control studies showed that ever HRT use can reduce 
A Study

ID

OR $(95 \% \mathrm{Cl}) \quad$ Weight, $\%$

\begin{tabular}{|c|c|c|c|}
\hline & 1 & & \\
\hline Yen-Li Lo2013 & & $0.75(0.63,0.91)$ & 20.27 \\
\hline Angela Cecilia Pesatori2013 & & $0.59(0.42,0.84)$ & 6.65 \\
\hline Cari L.Meinhold2011 & & $0.79(0.62,1.02)$ & 11.00 \\
\hline Kuan-Yu Chen2007 & & $0.63(0.48,0.82)$ & 10.50 \\
\hline N.Ramnath2007 & & $0.72(0.57,0.91)$ & 13.65 \\
\hline Ann G.Schwartz2007 & & $0.89(0.69,1.14)$ & 10.18 \\
\hline Matthew B.Schabath2004 & & $0.78(0.61,1.00)$ & 11.18 \\
\hline Alison M. Elliott2006 & & $0.92(0.47,1.79)$ & 1.44 \\
\hline Michaela Kreuzer2003 & & $0.75(0.60,0.93)$ & 15.14 \\
\hline Overall (1-squared $=0.0 \%, p=0.657$ ) & & $0.75(0.69,0.81)$ & 100.00 \\
\hline
\end{tabular}

B study

ID

OR $(95 \% \mathrm{Cl})$

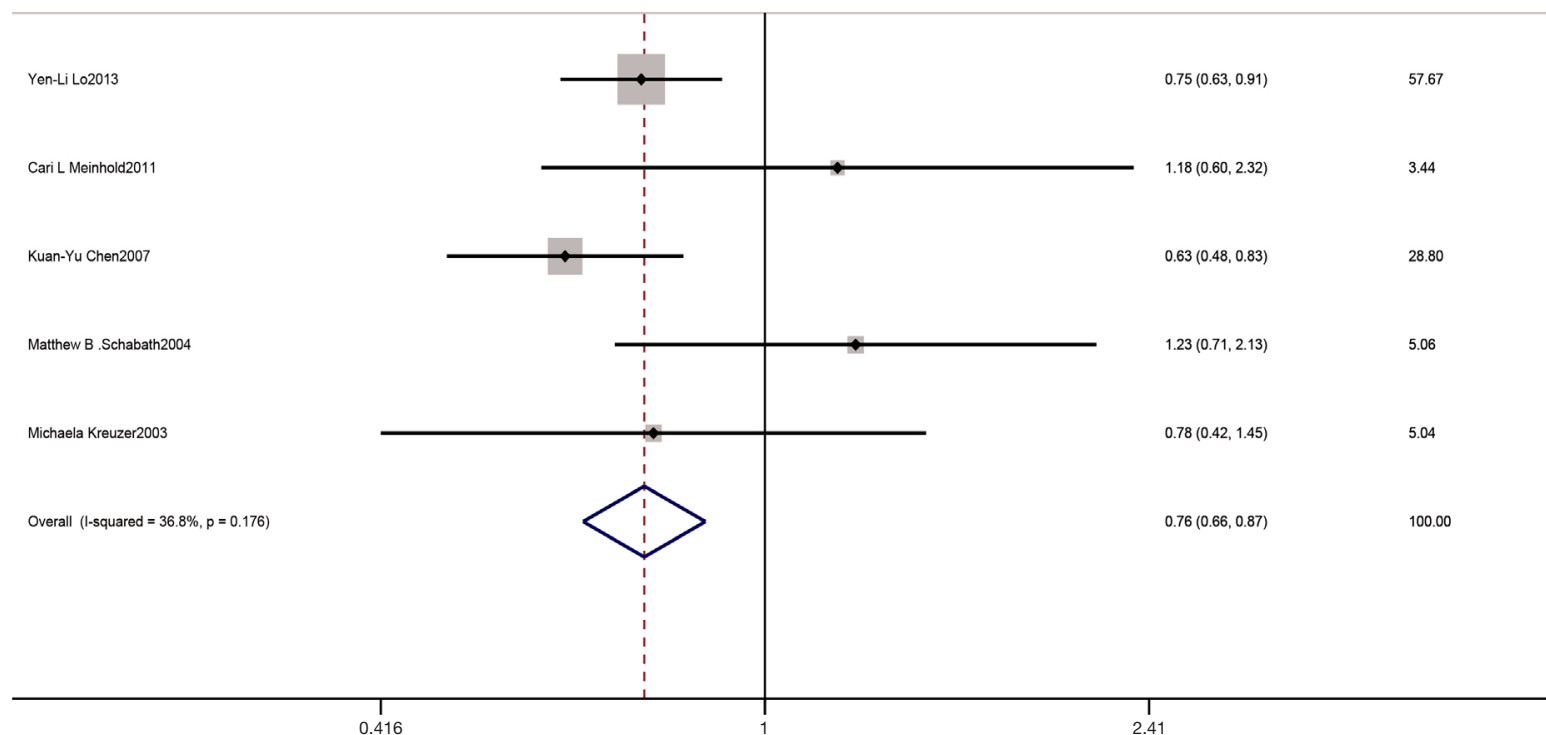

Figure 3 Forest plots of the association between the use of ever HRT and the risk of lung cancer in pooled case-control studies. (A) The association among all participants; (B) the association among female non-smokers. OR, odds ratio; CI, confidence interval; HRT, hormone replacement therapy. 


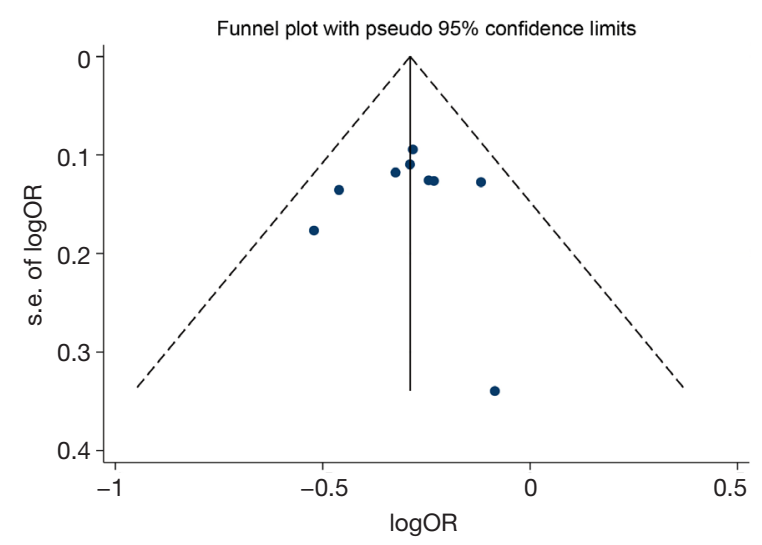

Figure 4 Funnel plots of the association between the use of ever HRT and the incidence of lung cancer in pooled case-control studies. HRT, hormone replacement therapy; OR, odds ratio. the incidence of lung cancer. However, in our pooled cohort studies, we did not find any statistical differences between ever HRT use and the incidence of lung cancer among all participants. This may be because of the different hormone receptor expression statuses and relevant genes SNPs of the participants. Schwartz et al. noted that HRT can reduce the risk of NSLC among estrogen receptor alpha (ER- $\alpha)$ and estrogen receptor beta (ER- $\beta$ ) positive patients (36). Cheng et al. pointed that women with higher nuclear ER- $\beta$ expression in the lung may be less likely to develop hormone-associated lung cancer (65). IGF-I is a peptide factor with mitotic activity, which is involved in regulating the proliferation, differentiation of many normal and cancer cells. Compared with never-HRT users, HRT users have lower plasma levels of insulin-like growth factor

Table 3 Summary RE and 95\% CI for the association between HRT and the risk of lung cancer

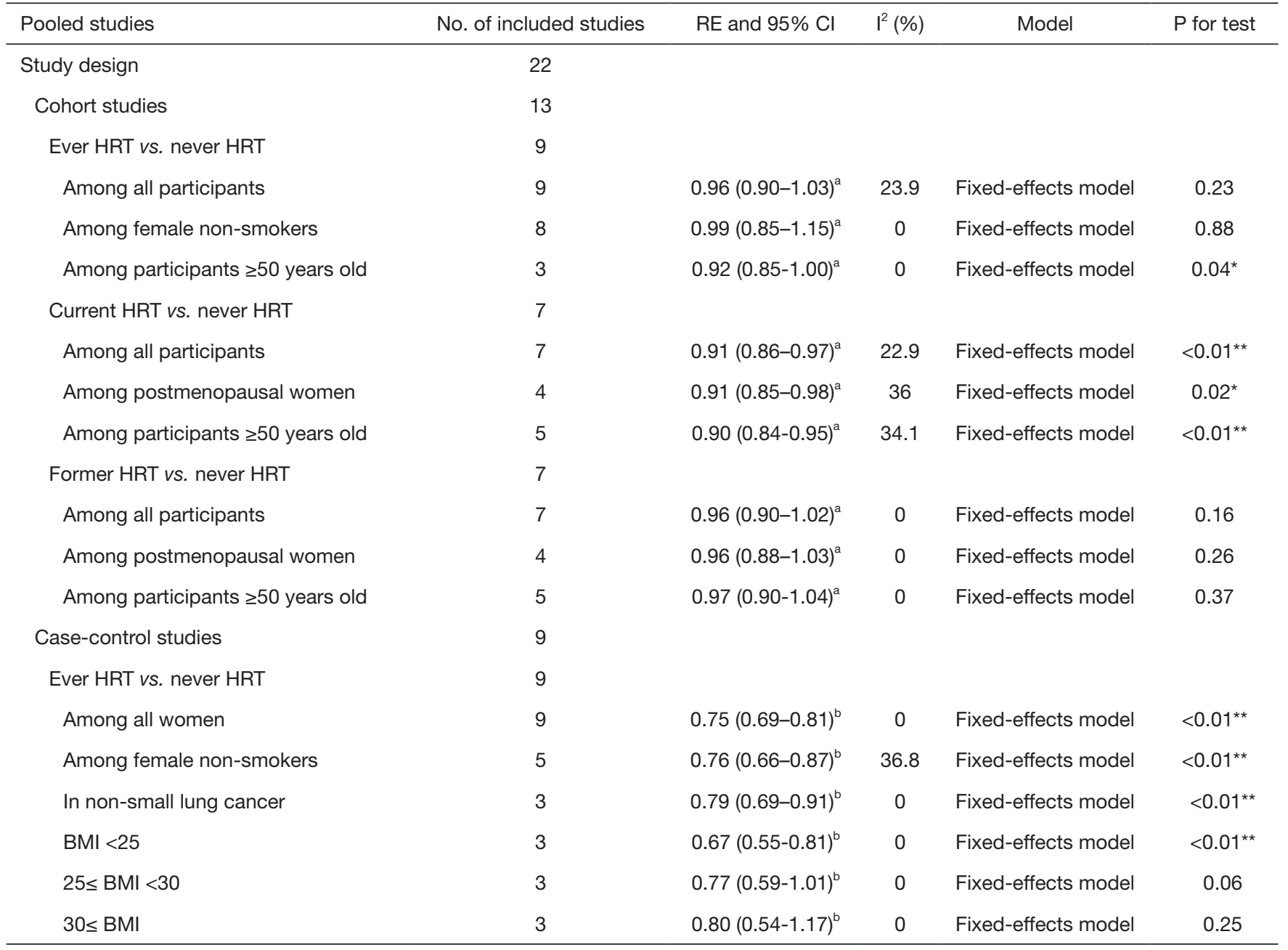

a , pooled relative risk; ${ }^{b}$, pooled odds ratio; *, $\mathrm{P} \leq 0.05$; ${ }^{\star \star}, \mathrm{P} \leq 0.01$. RE, risk estimates; $\mathrm{BMI}$, body mass index; $\mathrm{BMI}<25$, normal/underweight; $25 \leq \mathrm{BMI}<30$, overweight; $\mathrm{HRT}$, hormone replacement therapy; $30 \leq \mathrm{BMI}$, obese. 
I (39). Meanwhile, the EGFR SNP genotypes (rs7776830; rs4947995) have a cumulative effect on decreasing the risk of lung adenocarcinoma in female never smokers with HRT use (66).

Our pooled cohort studies suggested that the current use of HRT reduces the incidence of lung cancer. Thus, the concerns of peri- or postmenopausal women using current HRT to relieve peri- or postmenopausal syndromes about the incidence of lung cancer should be alleviated; however, considering the current HRT use was related to an increased risk of BC $(67,68)$, clinically multidisciplinary treatment decisions and joint decision-making for patients are required. Early and regular medical examinations still need to be conducted.

In our pooled case-control studies, non-smokers with ever HRT use had a low risk of lung cancer than no-HRT nonsmoking users, Cheng et al. pointed Smoking is associated with the increase of ER- $\alpha$ and ER- $\beta$ in the cytoplasm, hence non-smoking women may be less susceptible to hormone-related lung cancer for their hormone receptors' integrity (65), however, no relevant statistical differences were found in the pooled cohort studies. A reason for this contradiction may be related to genes. The sex hormone regulation-related SNP rs12233719 (Single Nucleotide Polymorphism), which is located in candidate gene $\mathrm{UGT}_{2} \mathrm{~B}_{7}$, may change SHBG(Sex Hormone-Binding Globulin) concentration and lead to NSCLC among Chinese neversmoking women (69). ER gene SNPs combined with HRT use could affect the risk of lung cancer in never-smoking women (70). It was necessary to test hormone receptor expression status, IGF-I level, relevant genes SNPs of each participant and find potential associations.

The effect of HRT on lung cancer mortality also remains controversial. A post hoc analysis showed that ever HRT use can reduce lung cancer mortality, compared with no HRT use (13). A follow-up study of 485 women showed that HRT use, especially estrogen plus progesterone use and long-term HRT use, was associated with the reduced risk in NSCLC among non-smokers and smokers (71). However, a post-hoc analysis of a randomized controlled trial showed that Estrogen plus progesterone in postmenopausal women can increase lung cancer deaths, especially in non-small cell lung cancer (72). Zhang et al. believed that HRT use was associated with increased lung cancer mortality (73). Progesterones are often considered as a component of HRT. In the progesterone receptor-positive NSCLC cells, progesterone can inhibit cell proliferation in a dose-dependent manner (74). Meanwhile, progesterone receptor (PR) polyproline domain (PPD) inhibited EGFR signaling in NSCLC (75). High nuclear ER- $\beta$ expression is correlated with non-small lung cancer EGFR mutations (76). Therefore, Different expressions in estrogen and progesterone receptor levels in female HRT users may lead to different outcomes.

More and more cancer survivors are seeking endocrine help in form of HRT; however, we are of the view that HRT use should be discontinued in patients diagnosed with lung cancer (77). Huang et al. (78) noted that the high expression of interleukin-6 stimulated by estrogen through the ER- $\beta$ pathway, which promotes the development of lung adenocarcinoma. Additionally, ER- $\alpha$ promotes macrophage infiltration, which increases the invasion of non-small lung cancer cells (79). Fan et al. (80) noted that estrogen promotes the metastasis of NSCLC by Toll-like receptor 4 upregulation through the ER- $\beta$. Thus, HRT should be prohibited in patients with lung cancer. Taking hormoneantagonizing drugs may improve the survival rate of lung cancer patients (81), and understanding estrogen biosynthesis genetic information may lead to the identification of novel ways to treat lung cancer (82). Meanwhile, the underlying mechanism also needs to be examined.

HRT can be administered by skin patches, injections or orally, and the administration of HRT may be continuous (every day), sequential (for part of each month), or less frequent. However, a large number of the original studies did not mention the type and frequency of administration. Thus, the effects of different types of HRT administration on lung cancer also need to be examined.

The pooled case-control studies showed that the concerns of women who ever use HRT to alleviate perior postmenopausal symptoms about the risk of lung cancer can be alleviated. The pooled cohort studies showed that current HRT use in women reduces the incidence of lung cancer, the same result in postmenopausal women with current HRT use. Due to the role of hormone receptors, hormone-related genes SNPs, and BC risk, clinical treatment decisions under a multidisciplinary approach will be more important and clinicians should pay more attention to individualized and targeted treatment.

This meta-analysis had some potential limitations. First, after the early termination of the Women's Health Initiative (WHI) trial in 2002 and the publication of the original WHI results on BC (83), although we have searched as many databases as possible, there might be a publication bias that could affect the results of our systematic review. Second, although we included a large 
number of prospective cohort trials but no randomized controlled trials were involved, the evidence of this metaanalysis might be weak or lacking. Hence, the associations should be further made by using data from randomized controlled studies. Third, a limitation of this analysis is that few published studies provided detailed information about HRT use and participants. Therefore, further research needs to be conducted on HRT administration types and the dosage of hormones among participants with different hormone receptors, IGF-I levels and relevant genes SNPs information.

\section{Conclusions}

Our meta-analysis showed that different HRT use can reduce the incidence of lung cancer to some extent. When perimenopausal and postmenopausal women use current HRT to reduce menopausal symptoms, concerns about the risk of lung cancer can be reduced. In our pooled casecontrol studies, we found ever HRT use was associated with the reduced incidence of lung cancer among female non-smokers and participants with $\mathrm{BMI} \leq 25$. Meanwhile, given the roles of hormone receptors, increased incidence of BC, and relevant genes SNPs, multidisciplinary clinical treatment decisions are required.

\section{Acknowledgments}

Funding: This study was supported by the Project of Tianjin Key Clinical Disciplines and the Project of Tianjin Health Commission (grant No. ZD20023) and the Project of Tianjin Science and Technology Innovation Bureau (grant No. 20JCYBJC01350).

\section{Footnote}

Reporting Checklist: The authors have completed the MOOSE reporting checklist. Available at https://jtd. amegroups.com/article/view/10.21037/jtd-22-48/rc

Conflicts of Interest: All authors have completed the ICMJE uniform disclosure form (available at https://jtd.amegroups. com/article/view/10.21037/jtd-22-48/coif). All authors report that this study was supported by the Project of Tianjin Key Clinical Disciplines and the Project of Tianjin Health Commission (grant No. ZD20023) and the Project of Tianjin Science and Technology Innovation Bureau (grant No. 20JCYBJC01350). The authors have no other conflicts of interest to declare.

Ethical Statement: The authors are accountable for all aspects of the work in ensuring that questions related to the accuracy or integrity of any part of the work are appropriately investigated and resolved.

Open Access Statement: This is an Open Access article distributed in accordance with the Creative Commons Attribution-NonCommercial-NoDerivs 4.0 International License (CC BY-NC-ND 4.0), which permits the noncommercial replication and distribution of the article with the strict proviso that no changes or edits are made and the original work is properly cited (including links to both the formal publication through the relevant DOI and the license). See: https://creativecommons.org/licenses/by-nc-nd/4.0/.

\section{References}

1. Deng Y, Zhao P, Zhou L, et al. Epidemiological trends of tracheal, bronchus, and lung cancer at the global, regional, and national levels: a population-based study. J Hematol Oncol 2020;13:98.

2. Sung H, Ferlay J, Siegel RL, et al. Global Cancer Statistics 2020: GLOBOCAN Estimates of Incidence and Mortality Worldwide for 36 Cancers in 185 Countries. CA Cancer J Clin 2021;71:209-49.

3. Siegel RL, Miller KD, Fuchs HE, et al. Cancer Statistics, 2021. CA Cancer J Clin 2021;71:7-33.

4. Duma N. Lung-cancer researchers and clinicians must pay more attention to women. Nature 2020;587:S13.

5. Wakelee HA, Chang ET, Gomez SL, et al. Lung cancer incidence in never smokers. J Clin Oncol 2007;25:472-8.

6. Couraud S, Zalcman G, Milleron B, et al. Lung cancer in never smokers--a review. Eur J Cancer 2012;48:1299-311.

7. Musial C, Zaucha R, Kuban-Jankowska A, et al. Plausible Role of Estrogens in Pathogenesis, Progression and Therapy of Lung Cancer. Int J Environ Res Public Health 2021;18:648.

8. Goodman NF, Cobin RH, Ginzburg SB, et al. American Association of Clinical Endocrinologists Medical Guidelines for Clinical Practice for the diagnosis and treatment of menopause. Endocr Pract 2011;17 Suppl 6:1-25.

9. Cagnacci A, Venier M. The Controversial History of Hormone Replacement Therapy. Medicina (Kaunas) 2019;55:602.

10. Lobo RA, Pickar JH, Stevenson JC, et al. Back to the 
future: Hormone replacement therapy as part of a prevention strategy for women at the onset of menopause. Atherosclerosis 2016;254:282-90.

11. Prentice RL, Aragaki AK, Chlebowski RT, et al. Randomized Trial Evaluation of the Benefits and Risks of Menopausal Hormone Therapy Among Women 50-59 Years of Age. Am J Epidemiol 2021;190:365-75.

12. Deli T, Orosz M, Jakab A. Hormone Replacement Therapy in Cancer Survivors - Review of the Literature. Pathol Oncol Res 2020;26:63-78.

13. Abdel-Rahman O. Lung cancer incidence and mortality in relationship to hormone replacement therapy use among women participating in the PLCO trial: a post hoc analysis. Int J Clin Oncol 2020;25:885-91.

14. Jin C, Lang B. Hormone replacement therapy and lung cancer risk in women: a meta-analysis of cohort studies: Hormone replacement therapy and lung cancer risk. Medicine (Baltimore) 2019;98:e17532.

15. Yao Y, Gu X, Zhu J, et al. Hormone replacement therapy in females can decrease the risk of lung cancer: a metaanalysis. PLoS One 2013;8:e71236.

16. Greiser CM, Greiser EM, Dören M. Menopausal hormone therapy and risk of lung cancer-Systematic review and meta-analysis. Maturitas 2010;65:198-204.

17. Oh SW, Myung SK, Park JY, et al. Hormone therapy and risk of lung cancer: a meta-analysis. J Womens Health (Larchmt) 2010;19:279-88.

18. Clague J, Reynolds P, Sullivan-Halley J, et al. Menopausal hormone therapy does not influence lung cancer risk: results from the California Teachers Study. Cancer Epidemiol Biomarkers Prev 2011;20:560-4.

19. Titan AL, He H, Lui N, et al. The influence of hormone replacement therapy on lung cancer incidence and mortality. J Thorac Cardiovasc Surg 2020;159:15461556.e4.

20. Schwartz AG, Ray RM, Cote ML, et al. Hormone Use, Reproductive History, and Risk of Lung Cancer: The Women's Health Initiative Studies. J Thorac Oncol 2015;10:1004-13.

21. Baik CS, Strauss GM, Speizer FE, et al. Reproductive factors, hormone use, and risk for lung cancer in postmenopausal women, the Nurses' Health Study. Cancer Epidemiol Biomarkers Prev 2010;19:2525-33.

22. Rodriguez C, Spencer Feigelson H, Deka A, et al. Postmenopausal hormone therapy and lung cancer risk in the cancer prevention study II nutrition cohort. Cancer Epidemiol Biomarkers Prev 2008;17:655-60.

23. Holm M, Olsen A, Kyrø C, et al. The Influence of
Menopausal Hormone Therapy and Potential Lifestyle Interactions in Female Cancer Development-a PopulationBased Prospective Study. Horm Cancer 2018;9:254-64.

24. Brinton LA, Schwartz L, Spitz MR, et al. Unopposed estrogen and estrogen plus progestin menopausal hormone therapy and lung cancer risk in the NIH-AARP Diet and Health Study Cohort. Cancer Causes Control 2012;23:487-96.

25. Seow A, Koh WP, Wang R, et al. Reproductive variables, soy intake, and lung cancer risk among nonsmoking women in the Singapore Chinese Health Study. Cancer Epidemiol Biomarkers Prev 2009;18:821-7.

26. Liu Y, Inoue M, Sobue $T$, et al. Reproductive factors, hormone use and the risk of lung cancer among middle-aged never-smoking Japanese women: a largescale population-based cohort study. Int J Cancer 2005;117:662-6.

27. Smith JR, Barrett-Connor E, Kritz-Silverstein D, et al. Hormone use and lung cancer incidence: the Rancho Bernardo cohort study. Menopause 2009;16:1044-8.

28. Tan HS, Tan MH, Chow KY, et al. Reproductive factors and lung cancer risk among women in the Singapore Breast Cancer Screening Project. Lung Cancer 2015;90:499-508.

29. Kabat GC, Miller AB, Rohan TE. Reproductive and hormonal factors and risk of lung cancer in women: a prospective cohort study. Int J Cancer 2007;120:2214-20.

30. Weiss JM, Lacey JV Jr, Shu XO, et al. Menstrual and reproductive factors in association with lung cancer in female lifetime nonsmokers. Am J Epidemiol 2008;168:1319-25.

31. Mirzakhani M, Shahbazi M, Akbari R, et al. Soluble CD30, the Immune Response, and Acute Rejection in Human Kidney Transplantation: A Systematic Review and Meta-Analysis. Front Immunol 2020;11:295.

32. Wei DM, Chen WJ, Meng RM, et al. Augmented expression of $\mathrm{Ki}-67$ is correlated with clinicopathological characteristics and prognosis for lung cancer patients: an up-dated systematic review and meta-analysis with 108 studies and 14,732 patients. Respir Res 2018;19:150.

33. Pan A, Wang Y, Talaei M, et al. Relation of Smoking With Total Mortality and Cardiovascular Events Among Patients With Diabetes Mellitus: A Meta-Analysis and Systematic Review. Circulation 2015;132:1795-804.

34. Lo YL, Hsiao CF, Chang GC, et al. Risk factors for primary lung cancer among never smokers by gender in a matched case-control study. Cancer Causes Control 2013;24:567-76.

35. Elliott AM, Hannaford PC. Use of exogenous hormones 
by women and lung cancer: evidence from the Royal College of General Practitioners' Oral Contraception Study. Contraception 2006;73:331-5.

36. Schwartz AG, Wenzlaff AS, Prysak GM, et al. Reproductive factors, hormone use, estrogen receptor expression and risk of non small-cell lung cancer in women. J Clin Oncol 2007;25:5785-92.

37. Chen KY, Hsiao CF, Chang GC, et al. Hormone replacement therapy and lung cancer risk in Chinese. Cancer 2007;110:1768-75.

38. Ramnath N, Menezes RJ, Loewen G, et al. Hormone replacement therapy as a risk factor for non-small cell lung cancer: results of a case-control study. Oncology 2007;73:305-10.

39. Schabath MB, Wu X, Vassilopoulou-Sellin R, et al. Hormone replacement therapy and lung cancer risk: a case-control analysis. Clin Cancer Res 2004;10:113-23.

40. Pesatori AC, Carugno M, Consonni D, et al. Reproductive and hormonal factors and the risk of lung cancer: the EAGLE study. Int J Cancer 2013;132:2630-9.

41. Meinhold CL, Berrington de González A, Bowman ED, et al. Reproductive and hormonal factors and the risk of nonsmall cell lung cancer. Int J Cancer 2011;128:1404-13.

42. Kreuzer M, Gerken M, Heinrich J, et al. Hormonal factors and risk of lung cancer among women? Int J Epidemiol 2003;32:263-71.

43. Schneeberger C, Stolk RP, Devries JH, et al. Differences in the pattern of antibiotic prescription profile and recurrence rate for possible urinary tract infections in women with and without diabetes. Diabetes Care 2008;31:1380-5.

44. Liu X, Zhou M, Wang F, et al. Secular Trend of Cancer Death and Incidence in 29 Cancer Groups in China, 1990-2017: A Joinpoint and Age-Period-Cohort Analysis. Cancer Manag Res 2020;12:6221-38.

45. Jeong SM, Lee DH, Giovannucci EL. Predicted lean body mass, fat mass and risk of lung cancer: prospective US cohort study. Eur J Epidemiol 2019;34:1151-60.

46. Wu S, Zhu W, Thompson P, et al. Evaluating intrinsic and non-intrinsic cancer risk factors. Nat Commun 2018;9:3490.

47. Shi J, Li D, Liang D, et al. Epidemiology and prognosis in young lung cancer patients aged under 45 years old in northern China. Sci Rep 2021;11:6817.

48. Wu S, Powers S, Zhu W, et al. Substantial contribution of extrinsic risk factors to cancer development. Nature 2016;529:43-7.

49. Ni X, Xu N, Wang Q. Meta-Analysis and Systematic Review in Environmental Tobacco Smoke Risk of Female
Lung Cancer by Research Type. Int J Environ Res Public Health 2018;15:1348.

50. Pandeya N, Wilson LF, Bain CJ, et al. Cancers in Australia in 2010 attributable to tobacco smoke. Aust N Z J Public Health 2015;39:464-70.

51. Yeung B, Yu J, Yang X. Roles of the Hippo pathway in lung development and tumorigenesis. Int J Cancer 2016;138:533-9.

52. Hu Y, Ren S, He Y, et al. Possible Oncogenic Viruses Associated with Lung Cancer. Onco Targets Ther 2020;13:10651-66.

53. Seltenrich N. Radon Risk: A Global Estimate of Radon's Contribution to Lung Cancer. Environ Health Perspect 2019;127:24001.

54. Yin X, Zhu Z, Hosgood HD, et al. Reproductive factors and lung cancer risk: a comprehensive systematic review and meta-analysis. BMC Public Health 2020;20:1458.

55. Zeng H, Yang Z, Li J, et al. Associations between female lung cancer risk and sex steroid hormones: a systematic review and meta-analysis of the worldwide epidemiological evidence on endogenous and exogenous sex steroid hormones. BMC Cancer 2021;21:690.

56. Xu L, Li L, Xu D, et al. Hormone replacement therapy in relation to the risk of colorectal cancer in women by BMI: a multicentre study with propensity score matching. Int J Clin Oncol 2022. [Epub ahead of print].

57. Jang YC, Huang HL, Leung CY. Association of hormone replacement therapy with mortality in colorectal cancer survivor: a systematic review and meta-analysis. BMC Cancer 2019;19:1199.

58. Xie SH, Santoni G, Lagergren J. Menopausal hormone therapy and risk of oesophageal adenocarcinoma in a population-based cohort study. Br J Cancer 2022;126:129-33.

59. Lagergren K, Lagergren J, Brusselaers N. Hormone replacement therapy and oral contraceptives and risk of oesophageal adenocarcinoma: a systematic review and meta-analysis. Int J Cancer 2014;135:2183-90.

60. Zhong GC, Liu Y, Chen N, et al. Reproductive factors, menopausal hormone therapies and primary liver cancer risk: a systematic review and dose-response metaanalysis of observational studies. Hum Reprod Update 2016;23:126-38.

61. Vargiu V, Amar ID, Rosati A, et al. Hormone replacement therapy and cervical cancer: a systematic review of the literature. Climacteric 2021;24:120-7.

62. Zhang X, Du Y, Tan X, et al. The Relationship Between Hormone Replacement Therapy and Risk of Kidney 
Cancer in Women: A Meta-Analysis. Cancer Control 2020;27:1073274820930194.

63. Camargo MC, Goto Y, Zabaleta J, et al. Sex hormones, hormonal interventions, and gastric cancer risk: a metaanalysis. Cancer Epidemiol Biomarkers Prev 2012;21:20-38.

64. Poggio F, Del Mastro L, Bruzzone M, et al. Safety of systemic hormone replacement therapy in breast cancer survivors: a systematic review and meta-analysis. Breast Cancer Res Treat 2022;191:269-75.

65. Cheng TD, Darke AK, Redman MW, et al. Smoking, Sex, and Non-Small Cell Lung Cancer: Steroid Hormone Receptors in Tumor Tissue (S0424). J Natl Cancer Inst 2018;110:734-42.

66. Chen KY, Hsiao CF, Chang GC, et al. EGFR polymorphisms, hormone replacement therapy and lung adenocarcinoma risk: analysis from a genome-wide association study in never-smoking women. Carcinogenesis 2013;34:612-9.

67. Jiang Y, Xie Q, Chen R. Breast Cancer Incidence and Mortality in Relation to Hormone Replacement Therapy Use Among Postmenopausal Women: Results From a Prospective Cohort Study. Clin Breast Cancer 2022;22:e206-13.

68. Rosenberg V, Bareket-Samish A, Chodick G, et al. Hormone-Replacement Therapy and Its Association with Breast Cancer Subtypes: A Large Retrospective Cohort Study. Int J Womens Health 2021;13:1207-16.

69. Qian Y, Xie L, Li L, et al. Association between sex hormones regulation-related SNP rs12233719 and lung cancer risk among never-smoking Chinese women. Cancer Med 2021;10:1880-8.

70. Chen KY, Hsiao CF, Chang GC, et al. Estrogen Receptor Gene Polymorphisms and Lung Adenocarcinoma Risk in Never-Smoking Women. J Thorac Oncol 2015;10:1413-20.

71. Katcoff H, Wenzlaff AS, Schwartz AG. Survival in women with NSCLC: the role of reproductive history and hormone use. J Thorac Oncol 2014;9:355-61.

72. Chlebowski RT, Schwartz AG, Wakelee H, et al. Oestrogen plus progestin and lung cancer in postmenopausal women (Women's Health Initiative trial): a post-hoc analysis of a randomised controlled trial. Lancet 2009;374:1243-51.

73. Zhang GQ, Chen JL, Luo Y, et al. Menopausal hormone therapy and women's health: An umbrella review. PLoS Med 2021;18:e1003731.

74. Ishibashi H, Suzuki T, Suzuki S, et al. Progesterone receptor in non-small cell lung cancer--a potent prognostic factor and possible target for endocrine therapy. Cancer
Res 2005;65:6450-8.

75. Kawprasertsri S, Pietras RJ, Marquez-Garban DC, et al. Progesterone receptor (PR) polyproline domain (PPD) mediates inhibition of epidermal growth factor receptor (EGFR) signaling in non-small cell lung cancer cells. Cancer Lett 2016;374:279-91.

76. He Q, Zhang M, Zhang J, et al. Correlation between epidermal growth factor receptor mutations and nuclear expression of female hormone receptors in nonsmall cell lung cancer: a meta-analysis. J Thorac Dis 2015;7:1588-94.

77. Siegfried JM. Hormone replacement therapy and decreased lung cancer survival. J Clin Oncol 2006;24:9-10.

78. Huang Q, Zhang Z, Liao Y, et al. $17 \beta$-estradiol upregulates IL6 expression through the ER $\beta$ pathway to promote lung adenocarcinoma progression. J Exp Clin Cancer Res 2018;37:133.

79. He M, Yu W, Chang C, et al. Estrogen receptor $\alpha$ promotes lung cancer cell invasion via increase of and cross-talk with infiltrated macrophages through the CCL2/CCR2/MMP9 and CXCL12/CXCR4 signaling pathways. Mol Oncol 2020;14:1779-99.

80. Fan S, Liao Y, Qiu W, et al. Estrogen promotes the metastasis of non-small cell lung cancer via estrogen receptor $\beta$ by upregulation of Toll-like receptor 4 and activation of the myd88/NF-кB/MMP2 pathway. Oncol Rep 2020. [Epub ahead of print].

81. Rodriguez-Lara V, Hernandez-Martinez JM, Arrieta O. Influence of estrogen in non-small cell lung cancer and its clinical implications. J Thorac Dis 2018;10:482-97.

82. Olivo-Marston SE, Mechanic LE, Mollerup S, et al. Serum estrogen and tumor-positive estrogen receptor-alpha are strong prognostic classifiers of non-small-cell lung cancer survival in both men and women. Carcinogenesis 2010;31:1778-86.

83. Rossouw JE, Anderson GL, Prentice RL, et al. Risks and benefits of estrogen plus progestin in healthy postmenopausal women: principal results From the Women's Health Initiative randomized controlled trial. JAMA 2002;288:321-33.

(English Language Editor: L. Huleatt)

Cite this article as: Wen H, Lin X, Sun D. The association between different hormone replacement therapy use and the incidence of lung cancer: a systematic review and meta-analysis. J Thorac Dis 2022;14(2):381-395. doi: 10.21037/jtd-22-48 


\section{Appendix 1}

Searching strategy was shown:

PubMed

((((((((((("Estrogens"[Mesh]) OR "Estrogens, Conjugated (USP)"[Mesh]) OR "Estradiol"[Mesh]) OR "estradiol valerate, cyproterone acetate drug combination" [Supplementary Concept]) OR "Progestins"[Mesh]) OR "Hormones"[Mesh]) OR "Hormones, Hormone Substitutes, and Hormone Antagonists"[Mesh]) OR "Gonadal Hormones"[Mesh]) OR "Gonadal Steroid Hormones"[Mesh]) OR "Estrogen Receptor Modulators"[Mesh]) OR "Estrogen Replacement Therapy"[Mesh]) OR "Raloxifene Hydrochloride"[Mesh]) OR "Hormone Replacement Therapy"[Mesh]

((((("Carcinoma, Bronchogenic"[Mesh]) OR ( "Small Cell Lung Carcinoma"[Mesh] OR "Carcinoma, Non-Small-Cell Lung"[Mesh] OR "Lung Neoplasms"[Mesh] ))

((((("Carcinoma, Bronchogenic"[Mesh]) OR ( "Small Cell Lung Carcinoma"[Mesh] OR "Carcinoma, Non-SmallCell Lung"[Mesh] OR "Lung Neoplasms"[Mesh] )) OR Abstract]) or(Carcinomas, Non-Small-Cell Lung[Title/Abstract])) OR (Carcinomas, Non-Small-Cell Lung[Title/Abstract])) OR (Lung Carcinomas, Non-Small-Cell[Title/Abstract])) OR (Non-Small-Cell Lung Carcinomas[Title/Abstract])) OR (Nonsmall Cell Lung Cancer[Title/Abstract])) OR (Non-Small-Cell Lung Carcinoma[Title/Abstract])) OR (Non Small Cell Lung Carcinoma[Title/Abstract])) OR (Carcinoma, Non-Small Cell Lung[Title/Abstract])) OR (Non-Small Cell Lung Cancer[Title/Abstract])) OR (Pulmonary Neoplasms[Title/Abstract])) OR (Neoplasms, Lung[Title/Abstract])) OR (Lung Neoplasm[Title/Abstract])) OR (Neoplasm, Lung[Title/Abstract])) OR (Neoplasms, Pulmonary[Title/Abstract])) OR (Neoplasm, Pulmonary[Title/Abstract])) OR (Pulmonary Neoplasm[Title/Abstract])) OR (Lung Cancer[Title/Abstract])) OR (Cancer, Lung[Title/Abstract])) OR (Cancers, Lung[Title/Abstract])) OR (Lung Cancers[Title/Abstract])) OR (Pulmonary Cancer[Title/Abstract])) OR (Cancer, Pulmonary[Title/Abstract])) OR (Cancers, Pulmonary[Title/Abstract])) OR (Pulmonary Cancers[Title/Abstract])) OR (Cancer of the Lung[Title/Abstract])) OR (Cancer of Lung[Title/Abstract])) OR (Small Cell Lung Cancer[Title/Abstract])) OR (Oat Cell Lung Cancer[Title/Abstract])) OR (Small Cell Cancer Of The Lung[Title/Abstract])) OR (Carcinoma, Small Cell Lung[Title/Abstract])) OR (Oat Cell Carcinoma of Lung[Title/ Abstract])) OR (Carcinoma, Bronchogenic[Title/Abstract]))))) AND ((("estrogenic compounds"[Title/Abstract] OR "compounds estrogenic"[Title/Abstract] OR "estrogenic agents"[Title/Abstract] OR "agents estrogenic"[Title/Abstract] OR "Estrogen"[Title/Abstract] OR "estrogen receptor agonists"[Title/Abstract] OR "agonists estrogen receptor"[Title/ Abstract] OR "agonists estrogen"[Title/Abstract] OR "estrogen effect"[Title/Abstract] OR "estrogenic effect"[Title/Abstract] OR "estrogenic effects"[Title/Abstract] OR "effects estrogenic"[Title/Abstract] OR "estrogen effects"[Title/Abstract] OR "effects estrogen"[Title/Abstract]) OR (((()((()((()((()((((Estradiol[Title/Abstract])) OR (Hormones[Title/Abstract])) OR (Hormones, Hormone Substitutes,[Title/Abstract] OR Hormone Antagonists[Title/Abstract])) OR (Progestins[Title/ Abstract])) OR (Therapy, Hormone Replacement[Title/Abstract])) OR (Hormone Replacement Therapies[Title/ Abstract])) OR (Replacement Therapies, Hormone[Title/Abstract])) OR (Therapies, Hormone Replacement[Title/ Abstract])) OR (Replacement Therapy, Hormone[Title/Abstract])) OR (Estrogen Replacement Therapies[Title/Abstract])) OR (Replacement Therapies, Estrogen[Title/Abstract])) OR (Therapies, Estrogen Replacement[Title/Abstract])) OR (Therapy, Estrogen Replacement[Title/Abstract])) OR (Replacement Therapy, Estrogen[Title/Abstract])) OR (Estrogen Replacement[Title/Abstract])) OR (Estrogen Replacements[Title/Abstract])) OR (Replacements, Estrogen[Title/Abstract])) OR (Replacement, Estrogen[Title/Abstract])) OR (Postmenopausal Hormone Replacement Therapy[Title/Abstract])) OR (Hormone Replacement Therapy, Post-Menopausal[Title/Abstract])) OR (Hormone Replacement Therapy, Post 
Menopausal[Title/Abstract])) OR (Estrogen Progestin Replacement Therapy[Title/Abstract])) OR (Estrogen Progestin Combination Therapy[Title/Abstract]))) OR (((((((((((("Estrogens"[Mesh]) OR "Estrogens, Conjugated (USP)"[Mesh]) OR "Estradiol"[Mesh]) OR "estradiol valerate, cyproterone acetate drug combination" [Supplementary Concept]) OR "Progestins"[Mesh]) OR "Hormones"[Mesh]) OR "Hormones, Hormone Substitutes, and Hormone Antagonists"[Mesh]) OR "Gonadal Hormones"[Mesh]) OR "Gonadal Steroid Hormones"[Mesh]) OR "Estrogen Receptor Modulators"[Mesh]) OR "Estrogen Replacement Therapy"[Mesh]) OR "Raloxifene Hydrochloride"[Mesh]) OR "Hormone Replacement Therapy"[Mesh]))

\section{Web of Science}

(TS=(Estrogenic Compounds OR Compounds, Estrogenic OR Estrogenic Agents OR Agents, Estrogenic OR Estrogen OR Estrogen Receptor Agonists OR Agonists, Estrogen Receptor OR Receptor Agonists, Estrogen OR Estrogen Effect OR Estrogenic Effect OR Estrogenic Effects OR Effects, Estrogenic OR Estrogen Effects OR Effects, Estrogen OR Estrogens, Conjugated OR Estradiol OR Estradiol 17 beta OR Progestins OR Progestagenic Agent OR Effect, Progestin OR Progestin Effect OR Hormones OR Hormones, Hormone Substitutes, and Hormone Antagonists OR Hormones, Gonadal OR Gonadal Hormone OR Hormone, Gonada OR Gonadal Steroid Hormones OR Estrogen Receptor Modulators OR Steroid Hormones, Gonadal OR Sex Steroid Hormone OR Hormone, Sex Steroid OR Steroid Hormone, Sex OR Sex Steroid Hormones OR Hormones, Sex Steroid OR Steroid Hormones, Sex OR Sex Hormone OR Hormone, Sex OR Sex Hormones OR Gonadal Steroid Hormone OR Estrogen Replacement Therapies OR Replacement Therapies, Estrogen OR Therapies, Estrogen Replacement OR Therapy, Estrogen Replacement OR Replacement Therapy, Estrogen OR Estrogen Replacement OR Estrogen Replacements OR Replacements, Estrogen OR Replacement, Estrogen OR Postmenopausal Hormone Replacement Therapy OR Hormone Replacement Therapy, Post-Menopausal OR Hormone Replacement Therapy, Post Menopausal OR Estrogen Progestin Replacement Therapy OR Estrogen Progestin Combination Therapy OR Raloxifene Hydrochloride OR Therapy, Hormone Replacement OR Hormone Replacement Therapies OR Replacement Therapies, Hormone OR Therapies, Hormone Replacement OR Replacement Therapy, Hormone) ) AND (Article) AND(TS=(Pulmonary Neoplasms OR Neoplasms, Lung OR Lung Neoplasm OR Neoplasm, Lung OR Neoplasms, Pulmonary OR Neoplasm, Pulmonary OR Pulmonary Neoplasm OR Lung Cancer OR Cancer, Lung OR Cancers, Lung OR Lung Cancers OR Pulmonary Cancer OR Cancer, Pulmonary OR Cancers, Pulmonary OR Pulmonary Cancers OR Cancer of the Lung OR Cancer of Lung OR Bronchogenic Carcinoma OR Bronchogenic Carcinomas OR Carcinomas, Bronchogenic OR Carcinoma, Bronchial OR Bronchial Carcinoma OR Bronchial Carcinomas OR Carcinomas, Bronchial OR Small Cell Lung Cancer OR Oat Cell Lung Cancer OR Small Cell Cancer Of The Lung OR Carcinoma, Small Cell Lung OR Oat Cell Carcinoma of Lung OR Carcinoma, Non Small Cell Lung OR Carcinomas, Non-Small-Cell Lung OR Lung Carcinoma, Non-Small-Cell OR Lung Carcinomas, Non-Small-Cell OR Non-Small-Cell Lung Carcinomas OR NonSmall-Cell Lung Carcinoma OR Non Small Cell Lung Carcinoma OR Carcinoma, Non-Small Cell Lung OR Non-Small Cell Lung Carcinoma OR Non-Small Cell Lung Cancer OR Non small Cell Lung Cancer))

Embase

('estrogen therapy' OR 'hormonal therapy' OR progesterone OR 'hormone substitution') AND 'lung cancer' AND [19662022]/py

Cochrane

\#1 MeSH descriptor: [Lung Neoplasms] explode all trees 
\#2 MeSH descriptor: [Hormone Replacement Therapy] explode all trees

\#3 lung cancer

\#4 hormone replacement therapy

\#5 estrogen replacement therapy

\#6 estrogen

\#7 progesterone

\#8 (\#1 OR \#3)

\#9 (\#2 OR \#4 OR \#5 OR \#6 OR \#7)

\#10 (\#8 AND \#9)

with Publication Year from 1800 to 2022, with Cochrane Library publication date from Jan 1800 to Dec 2022, in Trials

Scopus

( TITLE-ABS-KEY ( "Gonadal Hormones" ) OR TITLE-ABS-KEY ( "Gonadal Steroid Hormones" ) OR TITLEABS-KEY ( "Estrogen Receptor Modulators" ) OR TITLE-ABS-KEY ( "Estrogen Replacement Therapy" ) OR TITLEABS-KEY ( "Hormone Replacement Therapy" )) AND TITLE-ABS-KEY ( "lung cancer" ) )

China National Knowledge Infrastructure

(主题=肺癌) OR (关键词\%肺癌) OR (篇关摘\%肺癌) AND (篇关摘=激素替代治疗)

\section{WANGFANG}

全部:(肺癌) and 全部:(激素替代)) and Date:*2022

VIP

任意字段=肺癌 AND 任意字段=激素替代治疗 AND 年份：收录起始年-2022 


\section{Appendix 2}

Inclusion criteria (PICO format)

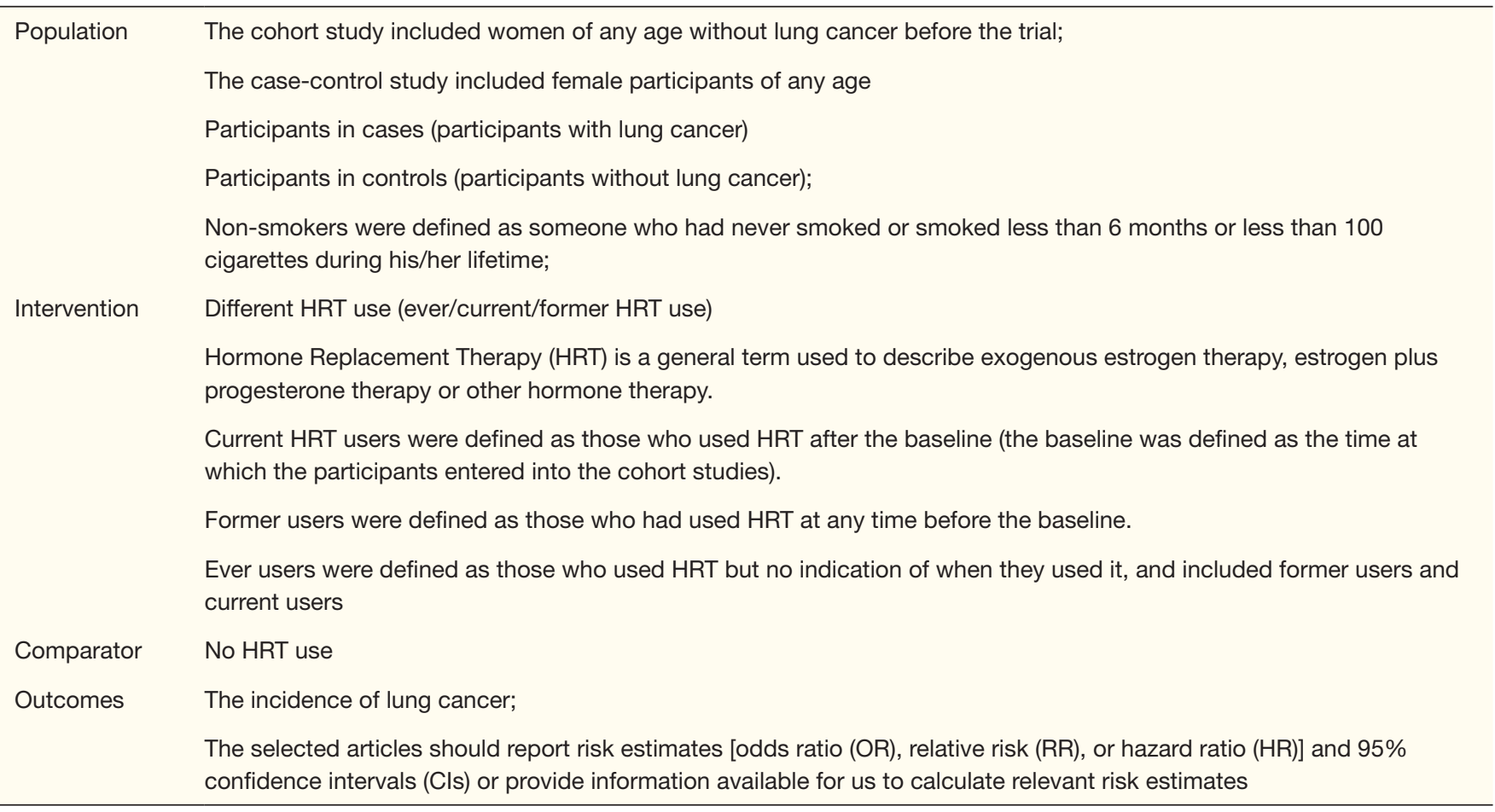

